ORIGINAL ARTICLE

\title{
Children with unexplained chronic pain: substantial impairment in everyday life
}

\author{
A Y Konijnenberg, C S P M Uiterwaal, J L L Kimpen, J van der Hoeven, J K Buitelaar, \\ E R de Graeff-Meeder
}

See end of article for authors' affiliations

\section{Correspondence to:} DrE R de Graeff-Meeder, University Medical Centre Utrecht, Department of Psychiatry, A00.241, PO Box 85500, $3508 \mathrm{GA}$ Utrecht, Netherlands: e.deGraeff-Meeder@ wkz.azu.nl

Accepted 19 August 2004 Published Online First 17 May 2005

Aims: To describe and quantify impairment in an outpatient population of children with chronic pain of unknown origin (UCP).

Methods: A total of 149 children who presented with pain of at least three months' duration and without a satisfactory explanation at presentation were studied. Number of somatic complaints (Children's Somatisation Inventory, CSI), pain intensity (VAS, 0-10 cm), functional disability (Child Health Questionnaire (CHQ-CF) and clinical history), and general health perceptions (CHQ) were determined. Results: Mean age of the children was 11.8 years; $73 \%$ were girls. Overall, $72 \%$ suffered impairment in sports activities, $51 \%$ reported absence from school, $40 \%$ experienced limitations in social functioning, and $34 \%$ had problems with sleeping. Mean number of somatic symptoms differed significantly between boys (8.4) and girls (10.7). The CHQ-CF scores for physical functioning, role/social functioning, and general health perceptions were 76.4, 70.7, and 57.5, respectively, indicating substantial impairment on all domains. The mean pain intensity was 4.7 for current and 7.1 for worst pain. Children solely evaluated by a general practitioner prior to referral reported less, though still substantial, impairment. Low general health perceptions, impaired role/social functioning, high pain intensity, and having headache or musculoskeletal pain were independent predictors of having significant impairment.

Conclusions: Referred children with UCP show substantial impairment on multiple domains in daily life.

C hronic pain is a common finding in childhood and adolescence. In a recent Dutch study $25 \%$ of a school per cent of these children consulted their general practitioner because of the pain. An additional $13.9 \%$ required specialist attention. $^{2}$ After referral, in a number of children a distinct explanation for the pain is evident at the first visit or shortly thereafter, and treatment, if applicable, can be started. However, when the symptoms remain medically unexplained, the diagnostic work-up becomes more complicated. A somatic aetiology can be identified in only $10-30 \%$ of the children with unexplained chronic pain (UCP). ${ }^{3-6}$ In everyday clinical practice UCP often is considered to be self-limiting and therefore innocuous. ${ }^{7}$ Although this may be true in some cases, there are indications that significant impairment and disabilities in daily life are present in children with UCP. ${ }^{8}$ High levels of functional disability were recently reported in patients selected from an outpatient paediatric pain clinic. ${ }^{9}$ A study comparing schoolchildren to children referred to a paediatric headache clinic showed those with headache to have more absence from school and more physical symptoms than children without headache. ${ }^{10}$

However, most previous research is performed in either children selected from the community by pain questionnaires or in subgroups of children in whom a complete somatic work-up had not yielded a diagnosis. These are obviously not representative for children with UCP first visiting a paediatric outpatient clinic.

In this study we therefore aimed to identify the impairment of children with UCP referred to an outpatient clinic of a university teaching hospital. Additionally, we assessed whether general patient characteristics, referral status (referred by a general practitioner or by a consultant physician or surgeon), and results from the Children's Somatisation Inventory and the Child Health Questionnaire modified this impact on daily life.

\section{METHODS}

The Pain of Unknown origin in Children Study (PUC study) was conducted between January 2000 and July 2002 in the Wilhelmina Children's Hospital, University Medical Centre Utrecht, Netherlands. Children who presented to the outpatient clinic were eligible when they met the following criteria: age 8-18 years; pain lasting at least three months prior to the visit and without an explanatory diagnosis set by the referring doctor; first visit to a university paediatric outpatient clinic for this complaint; and sufficient knowledge of the Dutch language. The Dutch healthcare system is organised such that a child is first evaluated by a general practitioner. If further specialised care is necessary the child can be referred to a regional or a university hospital. If specialists in the regional hospital need a second opinion, children can be referred to a university hospital. In the Netherlands, therefore, a university hospital to some extent covers the same population as a regional clinic. In our clinic approximately $30-50 \%$ of the outpatient population consists of children only evaluated by a general practitioner prior to referral. In this paper these are referred to as the general practitioner group (GP group). Children referred by a consultant physician or surgeon are denoted the consultant physician group (C group). Children were recruited from the department of general paediatrics, and the paediatric departments of neurology, orthopaedics, immunology and rheumatology, gastroenterology, and urology.

Abbreviations: CHQ-CF, Child Health Questionnaire Child Form; UCP, unexplained chronic pain; CSI, Children's Somatisation Inventory; $\mathrm{C}$ group, the group of children referred by a consultant physician or surgeon; GHP, General Health Perceptions (scale CHQ-CF); GP group, the group of children solely evaluated by their general practitioner prior to referral; PF, Physical Functioning (scale CHQ-CF); PPQ, Pediatric Pain Questionnaire; PUC study, Pain of Unknown origin in Children Study; RP, Role and Social Functioning (scale CHQ-CF); VAS, Visual Analogue Scale 


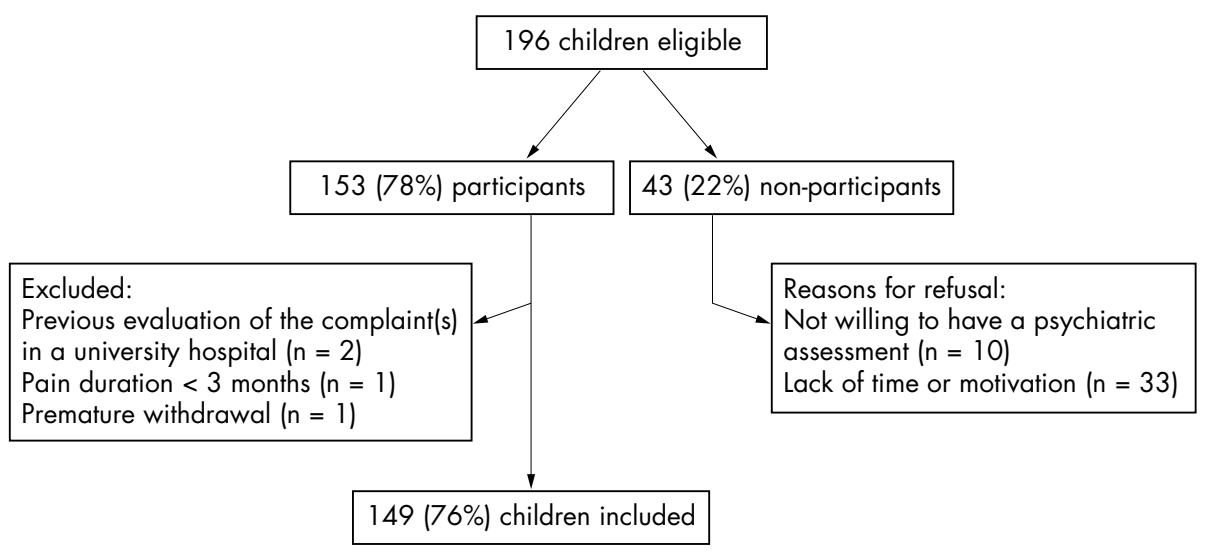

Figure 1 Flowchart inclusion procedure.

Eligible patients were approached and included immediately after their first and before their second visit to the outpatient clinic. Every child was evaluated at the discretion of the responsible physician. Only after each child and parent had given informed consent were additional research data gathered. (Semi)structured inquiries on the (previous) medical and family history were performed and supplemented with a physical examination.

Special attention was given to data related to the impact of pain on daily life: impairment in sports activities, absence from school, social impairment, and nocturnal awakening.

Impairment in sports activities was defined as having to quit, reduce, or change sports activities, because of the pain. A proportion of the children did not practise sports outside school. In those cases impairment in sports activities was based on impairment in school gymnastics.

Absence from school due to the pain was coded into predefined categories: no absence; less than once a month; 13 days a month; $1-3$ days a week; $1-4$ consecutive weeks; $1-3$ consecutive months; and more than 3 consecutive months. The cut-off point for school absence was set at the categories 13 days a month and higher. Social impairment was defined as either having to stop, reduce, or adjust the contact with peers, due to the physical complaints. Nocturnal awakening was coded as: no waking up; less than once a month; $1-3$ nights a month; 1-3 nights a week; and waking up every night.
Insomnia was defined as waking up at least 1-3 nights a month. Nocturnal awakening was only coded when it was said to be strictly related to the pain. Finally, these four domains were summed when coded "yes" to create a total impairment rate. Significant impairment was defined as interference on at least two out of the four domains.

Functional disability was assessed with three scales of the Child Health Questionnaire (CHQ). ${ }^{11}{ }^{12}$ Somatic complaints were evaluated with the Children's Somatisation Inventory (CSI). ${ }^{13}$ The Pediatric Pain Questionnaire (PPQ) was administered to record data concerning pain intensity. ${ }^{14}$ The study was approved by the Medical Ethics Committee of the University Medical Centre Utrecht.

\section{Measures}

The Children's Somatisation Inventory (CSI)

The CSI is a 35 item self-report inventory. ${ }^{15}$ The extent to which a child has been bothered by a symptom in the past two weeks was noted on a five point scale varying from $0=$ "not at all" to $4=$ "a whole lot". ${ }^{13}$ In our study a symptom was considered if rated 1 or higher. CSI outcomes were subsequently grouped into four subscales: neurological symptoms, cardiopulmonary symptoms, gastrointestinal symptoms, and pain symptoms. In addition, a corrected CSI total symptom score was computed in which those symptoms commonly associated with the primary complaint of the child were ignored. The CSI has been shown to have adequate test-retest reliability. ${ }^{16}$






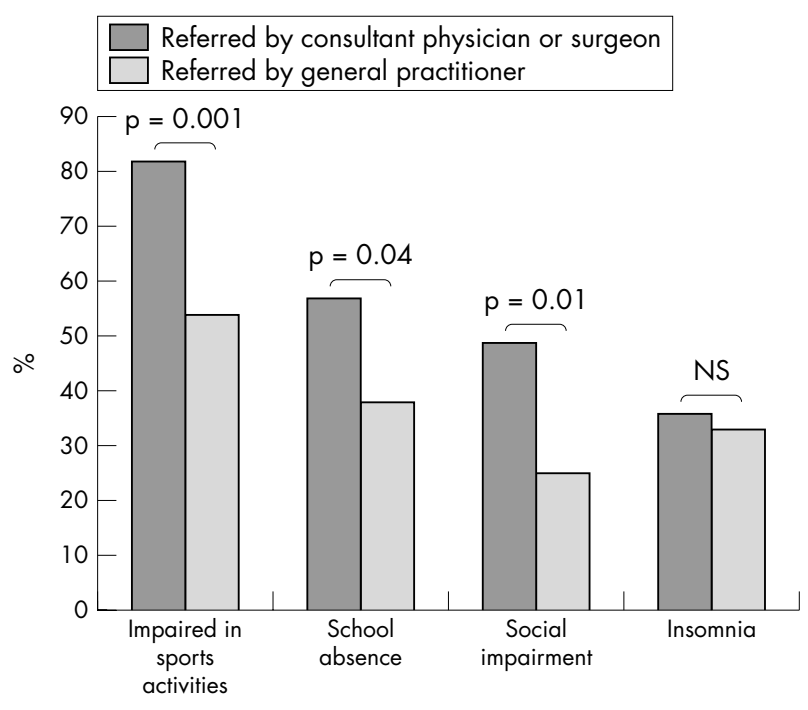

Figure 2 Impairments in daily life. The $x$-axis represents four domains of possible impairment: impairment in sports activities, absence from school, social impairment, and insomnia. The $y$-axis represents the proportion of children affected, subdivided by referral status: referred by the general practitioner (GP group) or referred by a consultant physician or surgeon (C group).

\section{The Child Health Questionnaire Child Form (CHQ-CF)}

The CHQ is a health status measure for children, which covers both physical and psychosocial domains. The questionnaire has been validated in over 32 countries, both in the general population and in chronically ill children. ${ }^{12}{ }^{17}{ }^{18}$ In our study the scales covering physical functioning, role/social limitations due to physical problems, and general health perceptions from the CHQ children's self-report form (CHQ$\mathrm{CF}$ ) were used. ${ }^{11}$ Scores range from 100, indicating no impairment at all, to zero, indicating very severe impairment. Low scores on the physical functioning scale reflect severe limitations in performing all physical activities, including self-care, due to the health condition. Low scores on the role/social scale indicate important limitations in schoolwork or activities with friends as a result of the health condition. Low scores on the general health perception scale reflect that the children believe that their health is poor and likely to get worse.

The Pediatric Pain Questionnaire (PPQ)

In this paper only the visual analogue scales (VAS) of the PPQ have been used. Children had to score their current pain level and the highest level of pain in the days preceding the completion of the questionnaire. The VAS ranged from $0=$ "no pain" to $10=$ "worst possible pain". The VAS has demonstrated validity for use in school aged children. ${ }^{19}$

\section{Data analysis}

For statistical analyses the Statistical software Package for Social Sciences, version 11.0 (SPSS 11.0) was used. Non-parametric methods (Kruskal-Wallis, Mann-Whitney $\mathrm{U})$ were used for analysis of questionnaire outcomes and pain duration, since these variables are not normally distributed. Proportional data were analysed from contingency tables with $\chi^{2}$ analysis. Univariate and multivariate (backward selection-likelihood method) logistic regression analyses were performed to assess the association of possible predictor variables with significant impairment. Results are displayed as odds ratios with corresponding 95\% confidence intervals. Statistical significance was assumed for $\mathrm{p}$ values $\leqslant 0.05$.

\section{RESULTS}

Figure 1 represents a flowchart of the inclusion procedure. The non-participants were more often boys ( $44 \%$ versus $28 \%$, $\chi^{2}=4.0, \mathrm{df}=1, \mathrm{p}=0.05$ ).

Table 1 shows the general patient characteristics. On average, the consultant physician group ( $\mathrm{C}$ group) reported higher current pain scores (mean 5.1 (SD 31) versus mean 3.8 (SD 3.1), $\mathrm{z}=-2.2, \mathrm{p}=0.03$ ) and longer pain duration (median 16.5 (range 3-144) versus median 8.0 (range 3$84), z=-2.72, p=0.007)$. The difference in pain intensity between the two groups was completely attributable to girls.

The majority of the children reported impairment on one or more domains in daily life (fig 2). Fourteen per cent (10/73) of the children with school absence missed out on school for three or more consecutive months. Social impairment was present in 40\% (54/134) of the children and mostly concerned less or adjusted contact with friends. Two children reported complete isolation from peers due to their pain. Sixty four per cent (31/48) of the children with nocturnal awakening reported disrupted sleep on a weekly basis. The GP group suffered significantly less impairment than the $\mathrm{C}$ group, although it was still considerable.

\section{The Children's Somatisation Inventory (CSI)}

The CSI could be analysed for 145 children and results are displayed in table 2. There were no significant differences between the GP group and the $\mathrm{C}$ group: mean number of complaints 10.7 (SD 6.0) versus 9.3 (SD 6.1) ( $\mathrm{z}=-1.3$, $\mathrm{p}=0.2$ ). Headache was the most frequently reported symptom (101/145), followed by low energy (92/145), abdominal pain (91/144), and arthralgia (87/144). Nausea, dizziness, and muscular pain were furthermore mentioned by at least $50 \%$ of the children. Girls reported more somatic symptoms, both in number and intensity. Both boys and girls reported symptoms related to different subscales: 58\% (84/ 145) reported symptoms on all subscales.

\section{The Child Health Questionnaire (CHQ)}

The majority of children showed limitations in everyday physical functioning (PF), role/social functioning (RP), and/ or general health perceptions (GHP) due to pain. Table 2 shows mean CHQ scale scores based on data from 135 analysable questionnaires. Children with musculoskeletal pain reported the severest impairment in physical functioning (72.2 versus 75.1 (headache) and 83.2 (abdominal pain), $\left.\chi^{2}=8.5, \mathrm{df}=2, \mathrm{p}=0.01\right)$. However, they had the highest general health perceptions (65.9 versus 45.9 (headache) and 53.9 (abdominal pain), $\chi^{2}=16.4, \quad \mathrm{df}=2, \quad \mathrm{p}=0.001$ ). Suffering from headache led to the highest interference with role/social functioning (50.9 versus 73.8 (abdominal pain) and 77.7 (muscular pain), $\chi^{2}=12.3, \mathrm{df}=2, \mathrm{p}=0.002$ ). Consistent with the previously reported impairment in sports activities (fig 1), the GP group reported less impairment on the physical functioning scale (mean 81.1 (SD 21.8) versus mean 74.1 ( $\mathrm{SD} 27.8$ ), $\mathrm{z}=-2.3, \mathrm{p}=0.02$ ). This group furthermore perceived their general health to be better (mean 64.6 (SD 19.4) versus mean 54.1 (SD 23.1), $\mathrm{z}=-2.4, \mathrm{p}=0.02)$.

\section{Total impairment}

Figure 3 displays the number of impaired domains in the children, subdivided by referral status. The $\mathrm{C}$ group reported impairment on significantly more domains (mean 2.04 (SD 1.2 ) versus mean 1.5 (SD 1.1), $\mathrm{z}=-2.8, \mathrm{p}=0.007)$. In both groups social impairment seemed to evolve relatively late, only after sports and school activities were affected. Univariate logistic regression analysis showed that chances for significant impairment (that is, interference on at least 
Table 2 Results of the Children's Somatisation Inventory and the Child Health Questionnaire

\begin{tabular}{lccc}
\hline & Girls & Boys & Total group \\
\hline Children's Somatisation Inventory & & & \\
Total number of symptoms (mean, SD) & $10.7(6.1)$ & $8.42(5.2)$ & $10.2(6.0) \dagger$ \\
Total number of intense symptoms reported (mean, SD)* & $3.6(3.3)$ & $2.6(3.2)$ & $3.3(3.3)$ \\
$\quad$ Number of subscales involved (mean, SD) & $3.3(1.0)$ & $3.2(1.0)$ & $3.3(1.0)$ \\
Child Health Questionnaire & $74.8(20.5)$ & $81.5(23.8)$ & $76.4(21.4)$ \\
Physical functioning (mean, SD) & $70.2(32.7)$ & $72.3(31.6)$ & $70.7(32.3)$ \\
Role/social functioning (mean, SD) & $56.1(23.1)$ & $62.1(20.1)$ & $57.5(22.5)$ \\
General health perceptions (mean, SD) & & \\
\hline
\end{tabular}

two domains in daily life) were higher if the child ( 1 ) was older, (2) suffered from headache or musculoskeletal pain, (3) was referred for academic evaluation, (4) reported more physical complaints, (5) reported impaired physical functioning, (6) reported impaired role/social functioning, (7) had lower general health perceptions, and (8) reported high levels of current or worst pain intensity (table 4). Although pain duration in itself was not a predictor for impairment, a notable finding was that in the GP group the duration of the pain prior to referral was shorter when the children were significantly impaired (15.7 versus 26.8 months, $\mathrm{z}=2.27, \mathrm{p}=0.02$ ). Independent predictors of impairment are displayed in table 4 .
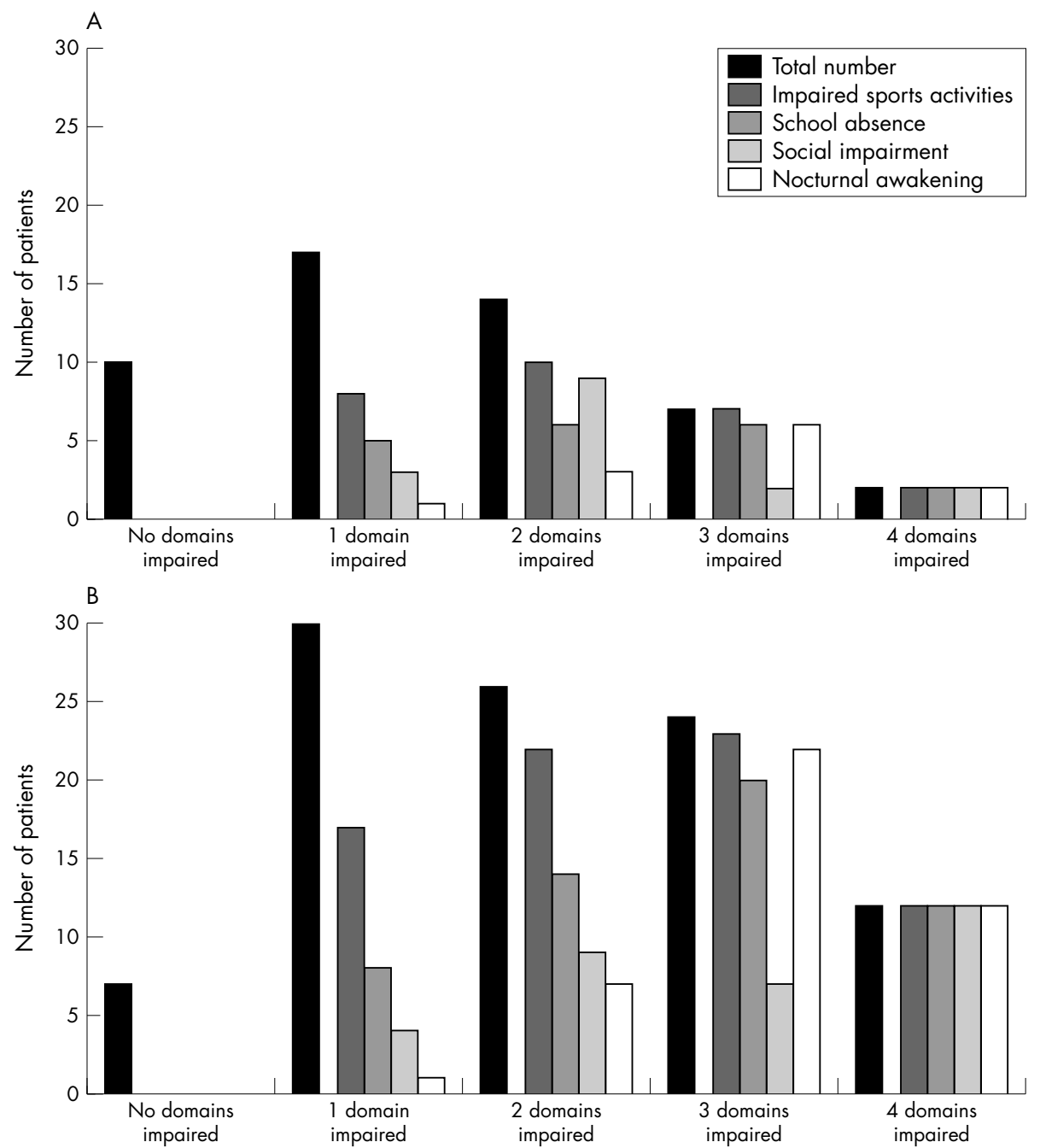

Figure 3 Number of impaired domains. The x-axis represents the number of impaired domains, subdivided by the relative contribution of the four domains counted: impairment in sports activities, absence from school, social impairment, and nocturnal awakening. The $y$-axis represents the number of children affected. (A) Data for children referred by a general practitioner (GP group, $n=50$ ). (B) Data for children referred by a consultant physician or surgeon (C group, $n=99$ ). 
Table 3 Univariate predictors of significant impairment (univariate logistic regression analysis)

\begin{tabular}{|c|c|c|}
\hline & OR $(95 \% \mathrm{Cl})$ & p value \\
\hline \multicolumn{3}{|l|}{ Patient characteristics } \\
\hline Age (years) & $1.15(1.0$ to 1.31$)$ & 0.04 \\
\hline \multicolumn{3}{|l|}{ Gender } \\
\hline Boy & Reference category & \\
\hline Girl & $1.48(0.7$ to 3.06$)$ & 0.29 \\
\hline \multicolumn{3}{|l|}{ Presenting symptom } \\
\hline Abdominal pain & Reference category & \\
\hline Headache & 3.83 (1.47 to 9.97$)$ & 0.006 \\
\hline Musculoskeletal pain & $2.52(1.19$ to 5.35$)$ & 0.02 \\
\hline Pain duration (months) & $1.0(0.99$ to 1.01$)$ & 0.54 \\
\hline \multicolumn{3}{|l|}{ Referral status* } \\
\hline GP group & Reference category & \\
\hline C group & 1.97 (0.99 to 3.92$)$ & 0.05 \\
\hline \multicolumn{3}{|l|}{ Questionnaires } \\
\hline Total number of complaints reported (CSI, range 0-30) & 1.11 (1.04 to 1.18$)$ & 0.001 \\
\hline Physical Functioning (CHQ, range $0-100)$ & $0.97(0.95$ to 0.99$)$ & 0.001 \\
\hline Role/Social Functioning $(\mathrm{CHQ}$, range $0-100)$ & $0.98(0.96$ to 0.99$)$ & $<0.001$ \\
\hline General Health Perceptions (CHQ, range 0-100) & 0.98 (0.96 to 0.99$)$ & 0.007 \\
\hline VAS current pain (mean, SD) & $1.25(1.11$ to 1.41$)$ & $<0.001$ \\
\hline VAS pain previous days (mean, SD) & $1.27(1.11$ to 1.45$)$ & 0.001 \\
\hline
\end{tabular}

\section{DISCUSSION}

Our study shows that children with UCP on intake report significant impairment in functioning on multiple domains in daily life. We evaluated children referred to a university teaching hospital for children and youth, in contrast to other clinical studies which are predominantly conducted in highly specialised pain settings. ${ }^{10}{ }^{20-25}$ Although our outpatient clinic is based in a university teaching hospital, $34 \%$ of our sample was only evaluated by a general practitioner prior to referral. Our results therefore are partly applicable to other, non-academic, hospital based situations.

This is the first study to evaluate children from an outpatient clinic without restriction to a specific pain condition and without focusing on a medical explanation for the pain. Wessely and others have recently stressed the importance of this conceptual approach and have pointed out that there might be much more communality between various pain syndromes than believed thus far. ${ }^{26}$

Some limitations of our study need to be addressed. Consistent with general findings in community based studies, the girls in our sample reported physical symptoms most frequently. ${ }^{1}$ However, the difference was not as large as expected and tended to disappear when CSI total scores were corrected for the primary complaint. Since our study is hospital based, differential referral might be an issue. Girls tend to seek medical care for their chronic pain sooner than boys do. ${ }^{2}$ Possibly those boys who eventually turn to medical services are the ones with the more severe complaints, thereby levelling differences. Due to the cross-sectional design of the study we are restricted to investigating temporal relations in our data and thus causal inferences cannot be made. Lastly, in retrieving our data we were forced to rely on the recollection of patients and their parents. Some recall bias therefore cannot be fully excluded.

Having addressed the above, a further elaboration on our data is possible.

Children from both the GP group and the $\mathrm{C}$ group reported substantial impairment in everyday life, although in the latter group significantly more impairment was encountered. In the GP group significant impairment was associated with shorter pain duration. Apparently, severity of impairment prompted referral earlier in the disease process.

Data on sleep disorders in the general population are sparse. In a school sample of children, $12 \%$ were self-reported problematic sleepers and $7.2 \%$ reported waking up at night very often. ${ }^{27}$ Although our results are not completely comparable due to differences in assessment techniques, it appears that children with UCP experience substantially more nocturnal awakening. School absence in our sample is comparable to or even higher than in children referred to

\begin{tabular}{|c|c|c|}
\hline & OR $(95 \% \mathrm{Cl})$ & $p$ value \\
\hline \multicolumn{3}{|l|}{ Patient characteristics } \\
\hline \multicolumn{3}{|l|}{ Presenting symptom } \\
\hline $\begin{array}{l}\text { Abdominal pain } \\
\text { Headache }\end{array}$ & $\begin{array}{l}\text { Reference category } \\
2.71 \text { (0.84 to } 8.72 \text { ) }\end{array}$ & 0.10 \\
\hline Musculoskeletal pain & 3.40 (1.30 to 8.87$)$ & 0.01 \\
\hline \multicolumn{3}{|l|}{ Questionnaires } \\
\hline Role/Social Functioning (CHQ, range 0-100) & $0.98(0.97$ to 1.0$)$ & 0.06 \\
\hline General Health Perceptions (CHQ, range 0-100) & $0.98(0.96$ to 0.99$)$ & 0.04 \\
\hline VAS pain previous days (mean, SD) & $1.19(1.02$ to 1.39$)$ & 0.02 \\
\hline
\end{tabular}




\section{What is already known on this topic}

- Unexplained chronic pain in children is a common finding

- Unexplained chronic pain in children is often considered to be innocuous

- A somatic aetiology can be found in $10-30 \%$ of the children

specialised pain clinics. ${ }^{920}$ Excessive absence from school may result in difficulties in completing academic work, being retained in the grade, and interference with social adjustment. ${ }^{28}{ }^{29}$ Disturbed sleep can further add to problematic school performance.

The CHQ-CF has been evaluated in a Dutch and Australian school sample. Within both samples, subgroups of children were identified suffering from two or more chronic somatic diseases. ${ }^{12}{ }^{30}$ The mean scores found in our group were markedly lower than those in both school samples. In addition, children with UCP reported considerably lower physical and role/social functioning compared to the school sample subgroups with chronic diseases. The general health perceptions were comparable in both groups. Thus, perceived limitations in referred children with UCP are far higher than in average schoolchildren and comparable to or worse than in children with somatic, chronic, diseases.

The mean number of physical complaints reported on the CSI is substantial, even when corrected for the primary symptom. A mean of 1.94 physical complaints was found in a large school sample when only complaints rated as "a lot" or "a whole lot" were considered. ${ }^{13}$ Our study focused on the presence of a symptom, rather than on its intensity. Being bothered by non-intense but constantly present physical signs or symptoms might be a burden in everyday life. Although to our knowledge no studies have been performed addressing this specific issue, there is circumstantial evidence to illustrate this view. ${ }^{31}$

A few independent indicators of significant impairment emerged from our data, mostly in the expected direction. What is remarkable in our opinion is that a poor belief in his/ her own health increased the chance for significant impairment in the child. Research has indeed shown that a patient's attribution to possible causes influences health related behaviour. ${ }^{32-34}$ It is furthermore recognised that those in control of their symptoms can better cope with bodily discomfort. ${ }^{35}$ Thus, when confronted with a child with UCP it might be to the child's benefit to inquire after the child's health beliefs. However, these results should still be interpreted with care given the cross-sectional nature of our study.

Especially in the light of long term outcome the impairment of referred children with UCP should be identified and acknowledged in an early phase. ${ }^{36-38}$ Future research should focus on unravelling the impairing mechanisms, such as psychiatric (co)morbidity, personality factors, family characteristics, and environmental stressors.

In conclusion, children with UCP suffer substantial impairment on several domains in daily life. These limitations are in part modified by main presenting symptom, role/ social functioning, pain intensity, and general health perceptions. So, even when only based on this impact on daily life, close and careful attention to these children is warranted.

\section{ACKNOWLEDGEMENTS}

All physicians and medical receptionists of the outpatient clinic of the Wilhelmina Children's Hospital, University Medical Centre Utrecht,

\section{What this study adds}

- Children with unexplained chronic pain report significant impairment in daily life

- Limitations are comparable to or worse than those of children with chronic somatic disorders

- Significant impairment can be predicted by, for instance, low general health perceptions

Netherlands are gratefully acknowledged for their contribution in recruiting the patients for this study.

\section{Authors' affiliations}

E R de Graeff-Meeder, Dept of Psychiatry, University Medical Centre Utrecht, Netherlands

A Y Konijnenberg, J L L Kimpen, Dept of General Paediatrics, University Medical Centre Utrecht, Netherlands

J van der Hoeven, Dept of Child and Adolescent Psychiatry, University Medical Centre Utrecht, Netherlands

C S P M Uiterwaal, Julius Centre for Health Sciences and Primary Care, Utrecht, Netherlands

J K Buitelaar, Dept of Psychiatry and Academic Centre for Child and Adolescent Psychiatry, UMC St Radboud, Nijmegen, Netherlands

Competing interests: none declared

\section{REFERENCES}

1 Perquin CW, Hazebroek-Kampschreur AA, Hunfeld JA, et al. Pain in children and adolescents: a common experience. Pain 2000;87:51-8.

2 Perquin CW, Hunfeld JA, Hazebroek-Kampschreur AA, et al. Insights in the use of health care services in chronic benign pain in childhood and adolescence. Pain 2001;94:205-13.

3 Apley J. The child with recurrent abdominal pain. Pediatr Clin North Am 1967; 14:63-72.

4 Hyams JS, Treem WR, Justinich CJ, et al. Characterization of symptoms in children with recurrent abdominal pain: resemblance to irritable bowel syndrome. J Pediatr Gastroenterol Nutr 1995;20:209-14.

5 van der Meer SB. Recurrent abdominal pain in children. Thesis. Rijksuniversiteit Limburg, The Netherlands, 1991.

6 McGhee J, Burks F, Sheckels J, et al. Identifying children with chronic arthritis based on chief complaints: absence of predictive value for musculoskeletal pain as an indicator of rheumatic disease in children. Pediatrics 2002; 110:354-9.

7 Malleson PN, Connell H, Bennett SM, et al. Chronic musculoskeletal and other idiopathic pain syndromes. Arch Dis Child 2001;84:189-92.

8 Flato B, Aasland A, Vandvik IH, et al. Outcome and predictive factors in children with chronic idiopathic musculoskeletal pain. Clin Exp Rheumatol 1997; 15:569-77.

9 Kashikar-Zuck S, Goldschneider KR, Powers SW, et al. Depression and functional disability in chronic pediatric pain. Clin J Pain 2001;17:341-9.

10 Smith MS, Martin-Herz SP, Womack WM, et al. Recurrent headache in adolescents: nonreferred versus clinic population. Headache 1999:39:616-24.

11 Landgraf JM, Abetz L, Ware JE. The CHQ user's manual. Boston, MA: The Health Institute, New England Medical Center, 1996.

12 Raat H, Bonsel GJ, Essink-Bot ML, et al. Reliability and validity of comprehensive health status measures in children. The Child Health Questionnaire in relation to the Health Utilities Index. I Clin Epidemiol 2002;55:67-76.

13 Garber J, Walker LS, Zeman J. Somatization symptoms in a community sample of children and adolescents: further validation of the children's Somatization Inventory. Psychol Assess 1991;3:588-95.

14 Abu-Saad HH, Pool H, Tulkens B. Further validity testing of the Abu-Saad Paediatric Pain Assessment Tool. J Adv Nurs 1994; 19:1063-71.

15 Treffers PhDA, Goedhart AW, Siebelink BM. Resultaten van de nederlandse vertaling van de Children's Somatization Inventory. In: Treffers PhDA, ed. Emotionele Stoornissen en Somatoforme Stoornissen bij kinderen en adolescenten: de stand van zaken. Leiden: Boerhaave Commissie voor Postacademisch Onderwiijs in de Geneeskunde, 1998:37-52.

16 Walker LS, Garber J, Greene JW. Somatization symptoms in pediatric abdominal pain patients: relation to chronicity of abdominal pain and parent somatization. J Abnorm Child Psychol 1991;19:379-94.

17 Ruperto N, Ravelli A, Pistorio A, et al. Cross-cultural adaptation and psychometric evaluation of the Childhood Health Assessment Questionnaire (CHAQ) and the Child Health Questionnaire (CHQ) in 32 countries. Review of the general methodology. Clin Exp Rheumatol 2001;19:S1-9. 
18 Wulffraat N, van der Net JJ, Ruperto N, et al. The Dutch version of the Childhood Health Assessment Questionnaire (CHAQ) and the Child Health Questionnaire (CHQ). Clin Exp Rheumatol 2001;19:S111-15.

19 Varni JW, Thompson KL, Hanson V. The Varni/Thompson Pediatric Pain Questionnaire. I. Chronic musculoskeletal pain in juvenile rheumatoid arthritis. Pain 1987;28:27-38.

20 Gladstein J, Holden EW. Chronic daily headache in children and adolescents: a 2-year prospective study. Headache 1996;36:349-51.

21 Holden EW, Gladstein J, Trulsen M, et al. Chronic daily headache in children and adolescents. Headache 1994;34:508-14.

22 Taimela S, Kujala UM, Salminen JJ, et al. The prevalence of low back pain among children and adolescents. A nationwide, cohort-based questionnaire survey in Finland. Spine 1997;22:1132-6.

23 Abu-Arefeh I, Russell G. Prevalence of headache and migraine in schoolchildren. BMJ 1994;309:765-9.

24 Hyams JS, Burke G, Davis PM, et al. Abdominal pain and irritable bowel syndrome in adolescents: a community-based study. J Pediatr 1996;129:220-6.

25 Macfarlane GJ, Morris S, Hunt IM, et al. Chronic widespread pain in the community: the influence of psychological symptoms and mental disorder on healthcare seeking behavior. J Rheumatol 1999;26:413-19.

26 Wessely S, Nimnuan C, Sharpe M. Functional somatic syndromes: one or many? Lancet 1999:354:936-9.

27 Ipsiroglu OS, Fatemi A, Werner I, et al. Self-reported organic and nonorganic sleep problems in schoolchildren aged 11 to 15 years in Vienna. J Adolesc Health 2002;31:436-42.

28 Klerman LV. School absence-a health perspective. Pediatr Clin North Am 1988;35:1253-69.
29 Anderson HR, Bailey PA, Cooper JS, et al. Morbidity and schoo absence caused by asthma and wheezing illness. Arch Dis Child 1983;58:777-84

30 Waters EB, Salmon LA, Wake M, et al. The health and well-being of adolescents: a school-based population study of the self-report Child Health Questionnaire. J Adolesc Health 2001;29:140-9.

31 Aronson KR, Barrett LF, Quigley KS. Feeling your body or feeling badly: evidence for the limited validity of the Somatosensory Amplification Scale as an index of somatic sensitivity. J Psychosom Res 2001;51:387-94.

32 Chalder T, Power MJ, Wessely S. Chronic fatigue in the community: 'a question of attribution'. Psychol Med 1996;26:791-800.

33 Garralda ME, Bowman FM, Mandalia S. Children with psychiatric disorders who are frequent attenders to primary care. Eur Child Adolesc Psychiatry 1999;8:34-44.

34 Campo JV, Comer DM, Jansen-McWilliams L, et al. Recurrent pain, emotional distress, and health service use in childhood. J Pediatr 2002;141:76-83.

35 Reid GJ, Gilbert CA, McGrath PJ. The Pain Coping Questionnaire: preliminary validation. Pain 1998;76:83-96.

36 Hotopf M, Carr S, Mayou R, et al. Why do children have chronic abdominal pain, and what happens to them when they grow up? Population based cohort study. BMJ 1998;316:1196-200.

37 Fearon $\mathrm{P}$, Hotopf M. Relation between headache in childhood and physical and psychiatric symptoms in adulthood: national birth cohort study. BMJ 2001;322:1-6.

38 Campo JV, Di Lorenzo C, Chiappetta L, et al. Adult outcomes of pediatric recurrent abdominal pain: do they just grow out of it? Pediatrics 2001;108:el

\section{bmjupdates+}

bmjupdates+ is a unique and free alerting service, designed to keep you up to date with the medical literature that is truly important to your practice.

bmjupdates+ will alert you to important new research and will provide you with the best new evidence concerning important advances in health care, tailored to your medical interests and time demands.

Where does the information come from?

bmjupdates+ applies an expert critical appraisal filter to over 100 top medical journals A panel of over 2000 physicians find the few 'must read' studies for each area of clinical interest

Sign up to receive your tailored email alerts, searching access and more...

www.bmjupdates.com 